\title{
Study on Ferric Chloride Coagulation Process and Fenton's Reaction for Pretreatment of Dairy Wastewater
}

\author{
Omnya A. El-Battrawy, Mervat A. El-Sonbati, Ebtesam M. El-Awadly and Talaat A. \\ Hegazy
}

Department of Environmental Sciences, Faculty of Science, Damietta University, Egypt. Received: 30 Nov. 2019 / Accepted 05 Feb. 2020 / Publication date: 25 Feb. 2020

\begin{abstract}
Nowadays, much attention is given to dairy industries wastewaters because of their upward pollution potential arising out of the industrialization and numerous anthropogenic activities. Unplanned discharge of wastewaters to waterways can prompt environmental damage. Therefore, treatment is necessary prior discharge or reuse of water. This research work on the laboratory scale is utilized for the characterization and evaluation of the efficiency of chemical coagulation followed by advanced oxidation process as a pretreatment technique for dairy industries wastewaters. Three composite wastewater samples were collected from diary industries plant at New Damietta City during the year 2018 and characterized for some physicochemical parameters to check their pollution potential. One sample is chosen and subjected to pretreatment using chemical coagulation/ precipitation by $\mathrm{FeCl}_{3}$ with lime and polyacrylamide as coagulant aides followed by advanced oxidation process with Fenton's reagent. The results showed that concentration of chemical oxygen demand is $76800 \mathrm{mg} / \mathrm{L}$ while for biochemical oxygen demand is $60000 \mathrm{mg} / \mathrm{L}$. Removal efficiency of COD after applying $\mathrm{FeCl}_{3} /$ lime was $(94.2 \%)$ while for $\mathrm{FeCl}_{3} /$ polyacrylamide was $(70 \%)$. The optimum conditions of Fenton's reaction were $30 \mathrm{ml} / \mathrm{L}\left(\mathrm{H}_{2} \mathrm{O}_{2}\right)$ and $\mathrm{pH} 7.35$ that achieved $95 \%$ of COD removal. It's concluded that using Fenton oxidation process after coagulation by $\mathrm{FeCl}_{3}$ with lime was found a little enhancement in the COD removal of dairy wastewater effluents.
\end{abstract}

Keywords: Dairy effluents, physicochemical parameters, coagulant aides, lime, COD removal.

\section{Introduction}

The dairy industry is one of the most contaminating of industries in terms of effluent volume produced and its characteristics as well. Numerous dairies of various sizes have come up in different places as a result of increasing demand for milk and milk products (Sivaprakasam and Balaji, 2019). Dairy processing effluents are produced in an irregular manner and the flow rates of these effluents change considerably (Shete and Shinkar, 2013). The nature and composition of wastes relies upon type of goods produced and processing capacity of the plants (Jain et al., 2018).

Dairy wastewaters are characterized by high levels of chemical oxygen demand (COD) and biochemical oxygen demand (BOD) (Patil and Hugar, 2015). The ratio COD / BOD shows the biodegradability of organic materials in aerobic or anaerobic condition (Suman et al., 2017). Dairy wastewater is often discharged intermittently to the near stream or land without earlier treatment causing serious pollution issues. Dairy effluents deplete rapidly the dissolved oxygen level bringing about anaerobic conditions of the receiving streams and release of foul odors (Prazeres et al., 2013).

Dairy wastewater should be pretreated before biological treatment due to the presence of detergents and oil and grease that encourage the creation of filamentous organisms which forms scum and foam layers in the aeration tanks and finally inhibit the treatment process (Ying et al., 2002). In addition, adsorption of oil and grease on the sludge surface may constrain the exchange of oxygen and soluble substrates to biomass which prompts decrease in the rate of substrate conversion (Farizoglu and Uzuner, 2011)

Coagulation/flocculation is a commonly utilized process in water and wastewater treatment (Khouni et al., 2011) in which coagulants such as ferric chloride and/or polymer are provided to wastewater to destabilize the colloidal materials and allow small particles to agglomerate into larger settleable flocs (Amud and Amoo, 2007). $\mathrm{FeCl}_{3}$ is a significant coagulant in wastewater treatment and

Corresponding Author: Omnya A. El-Batrawy, Associate Professor, Environmental Sciences Department, Faculty of Science, Damietta University, New Damietta City, Box 34517, Damietta, Egypt. E-mail: om_elbattrawy@du.edu.eg 
can be utilized for decolourization (Papic et al., 2000), treatment of organic pollutants (Jain et al., 2018), treatment of detergent wastewater (Aygun and Yilmaz 2010), treatment of petrochemical industries wastewater (Altaher et al., 2011), and treatment of diary wastewater (Prazeres et al., 2013). Coagulation/flocculation has a preference in the primary treatment processes mostly because of the ease of operation, high efficiency, and cost effective (AlMubaddal et al., 2009).

The application of advanced oxidation processes (AOPs) after the chemical and/or biological processes can establish a promising alternative to reduce recalcitrant organic matter, principally, because of the formation of hydroxyl radicals (Aygun and Yilmaz 2010). These radicals, acts as powerful oxidizing agents, and have enough potential to efficiently destruct pollutants and make wastewater less toxic (Ahmad et al., 2016). The Fenton process is a widely applied AOP which is a mixture of ferrous/ferric iron (catalyst) and hydrogen peroxide (oxidizing agent) (Gu et al., 2013).

This work is conducted to investigate the efficiency of chemical coagulation using ferric chloride with lime and polyacrylamide as coagulant aides as a pretreatment techniques for dairy industries wastewater. The optimum conditions were determined for $\mathrm{FeCl}_{3}$ with both coagulant aids. The efficiency of advanced oxidation process using Fenton reagent after coagulation with $\mathrm{FeCl}_{3}$ and lime was also optimized and evaluated. Emphasis will be given to the removal efficiency of the COD.

\section{Materials and Methods}

\section{Sampling Site}

The wastewater samples were collected from a plant for manufacturing dairy products located in the industrial Zone of New Damietta City, Damietta, Egypt. Three composite water samples (S1S3) were collected during the year 2018 according to the availability of sampling. The samples were collected in high density polyethylene (HDPE) containers that were routinely acid-treated and well rinsed with de-ionized water prior to use, dried, and stored with the caps on to prevent contamination.

\section{Physico-Chemical Characterization}

All the dairy wastewater samples were characterized for some physicochemical parameters such as pH, Electrical Conductivity (EC), Turbidity, Salinity, Total Solids (TS), Total Dissolved Solids (TDS), Dissolved Oxygen (DO), Biological Oxygen Demand (BOD), Chemical Oxygen Demand (COD), Oil \& Grease, Total Nitrogen (TKN), Total Phosphorus (TP), and have been determined according to Standard Method (APHA, 2017). The $\mathrm{pH}$ of the samples was measured directly by $\mathrm{pH}$ Meter (model, 211 HANNA, USA). Salinity, Electric conductivity (EC) and Total Dissolved Solids (TDS) of the samples were determined by Digital Portable TDS/ Conductivity meter (Model 8033 HANNA,USA).Turbidity of samples was measured by Turbidimeter (A11000 aqualytic Germany with measuring 0-200 NTU). The Total Solids (TS) are determined by the evaporation of a sample at $\left(105^{\circ} \mathrm{C}\right)$ according to the method of Adams (1991).

\section{Coagulation/Precipitation $(\mathrm{C} / \mathrm{P})$ Process}

Sample (S3) was chosen to be subjected to pretreatment processes using $\mathrm{FeCl}_{3}$ as coagulants where lime and polyacrylamide as coagulants aids. Lime was used after conversion to milk-of-lime which is slurry of $\mathrm{Ca}(\mathrm{OH})_{2}$ in water (Asadi, 2006). The optimum condition ( $\mathrm{pH}$, doses, etc.,) were determined for both $\mathrm{FeCl}_{3}$ and coagulant aides. Chemical coagulation experiments were conducted with the jar test according to Rump (1999). Six beakers containing $1000 \mathrm{~mL}$ dairy industries wastewaters sample were placed on a standard jar test apparatus. A flash/rapid mixing at $100 \mathrm{rpm}$ for 2 min was carried out after adding the coagulant dose; then the slow mixing was carried out at $20 \mathrm{rpm}$ for $25 \mathrm{~min}$. Thereafter, jars were kept standstill for $20 \mathrm{~min}$ to settle down the flocs. A series of jar tests were performed to determine the effect of coagulant, coagulant aids doses and initial $\mathrm{pH}$ on COD removal from dairy industries wastewaters. The removal percent of COD was calculated (Eq. 1).

Removal \% $=\frac{C i-C f}{C i} \times 100$

where $c_{i}$ and $c_{f}$ are the initial and final COD concentration, respectively. 


\section{Advanced Oxidation Process by Fenton's Reagent}

The Fenton's reagent was prepared according to (Benatti and Tavares, 2014) which consists of $\mathrm{H}_{2} \mathrm{O}_{2}$, ferrous ions with $\mathrm{pH}$ adjustment. Fenton's reaction was applied on the dairy wastewater after $\mathrm{C} / \mathrm{P}$ with $\mathrm{FeCl}_{3}$ and lime. The effects of ferrous ion, hydrogen peroxide concentration and $\mathrm{pH}$ on the treatment of the dairy industries wastewater were investigated. All experiments were performed in a Jar Test apparatus (Rump, 1999).

\section{Results and Discussion}

\section{Physico-Chemical Characterization}

The characterization of the dairy industries wastewater samples was shown in Table (1). The results showed that concentration of COD ranged from 20520 to $76800 \mathrm{mg} / \mathrm{L}$ while BOD ranged from 14290 to $60000 \mathrm{mg} / \mathrm{L}$. Oil and grease, TP, TKN and TS are $(672.4-774.8 \mathrm{mg} / \mathrm{L}),(3133-5193.11$ $\mathrm{mg} / \mathrm{L}),(1424-1772.5 \mathrm{mg} / \mathrm{L})$ and $(11732-131686 \mathrm{mg} / \mathrm{L})$, respectively. The broad range of the concentrations of the investigated parameters of samples may be attributed to the differences of organic content of dairy wastewater during the year (Slavov, 2017). The high organic load was mainly due to dissolved milk protein and sugars. Tawfik et al. (2008) studied wastewaters from Arab Dairy Factory and found COD, BOD and TS $(3383 \pm 1345 \mathrm{mg} / \mathrm{L}),(1941 \pm 864 \mathrm{mg} / \mathrm{L})$, and $(831 \pm 392 \mathrm{mg} / \mathrm{L})$, respectively. Deshannavar et al. (2012) examined wastewaters from Dairy effluent and found that the concentration of COD, BOD and TS were (1900-2700 mg/L), (1200-1800 mg/L), and (900-1350 $\mathrm{mg} / \mathrm{L})$, respectively.

Table 1: The physicochemical characterization of the dairy industries wastewater samples.

\begin{tabular}{lcccc}
\hline \multicolumn{1}{c}{ Parameter } & Unit & S1 & S2 & S3 \\
\hline pH & - & 5.99 & 4.56 & 4.35 \\
Total Dissolved Solids (TDS) & $\mathrm{g} / \mathrm{L}$ & 41.5 & 41.8 & 34.2 \\
Electrical Conductivity (EC) & $\mathrm{ms} / \mathrm{cm}$ & 50.9 & 54.1 & 48 \\
Salinity & $\%$ & 42.8 & 43 & 35.7 \\
Turbidity & $\mathrm{NTU}$ & 100 & 3595 & 2505 \\
BOD & $\mathrm{mg} / \mathrm{L}$ & 14290 & 35000 & 60000 \\
COD & $\mathrm{mg} / \mathrm{L}$ & 20520 & 70400 & 76800 \\
Oil and grease & $\mathrm{mg} / \mathrm{L}$ & 672.4 & 774.8 & 723.8 \\
Total Phosphorous (TP) & $\mathrm{mg} / \mathrm{L}$ & 10636 & 5193.11 & 3133.4 \\
Total Solids (TS) & $\mathrm{mg} / \mathrm{L}$ & 127818 & 131686 & 117312 \\
TKN & $\mathrm{mg} / \mathrm{L}$ & 1682.54 & 1772.5 & 1424.606 \\
\hline
\end{tabular}

\section{Coagulation/Precipitation Process}

Coagulation and flocculation are the procedures used to remove the particles responsible for colour and turbidity. The colloidal particles found in wastewaters generally have a negative electrical charge and are surrounded by an electrical double layer because of attachment of positively charged ions from the surrounding solution. They remain suspended because of their low specific gravity. Coagulants are added to flocculate colloidal particulates into bigger particles that can be evacuated by sedimentation or flotation (Loloei et al., 2019).

The effect of ferric chloride concentration $(0-0.6 \mathrm{~g} / \mathrm{L})$ on the coagulation process was critically examined (Fig. 1). It is obvious that, COD removal percentage increased from 33.2 to $51.4 \%$ with increasing ferric chloride dose up to $0.1 \mathrm{~g} / \mathrm{L}$. This may be attributed to increase the super saturation of Fe $(\mathrm{OH})_{3}$ which improved the nucleation rate and consequently the floc growth rate. Therefore, removal of larger amounts of COD was attained because of the availability of bigger surface area on which organic matter adsorption occurred. On the contrary, low doses of $\mathrm{FeCl}_{3}$ prompted the development of larger but fewer flocs because of faster growth rate comparative with nucleation rate resulting in a smaller surface area (Amud and Amoo, 2007). Increasing the ferric chloride dose over $0.4 \mathrm{~g} / \mathrm{L}$ exerts adverse effect in the coagulation efficiency. Therefore, the optimum ferric chloride dose that improved COD removal will not exceed $0.1 \mathrm{~g} / \mathrm{L}$. Moreover, the percent removal of COD at zero ferric chloride dose is $33.2 \%$, this due to plain sedimentation, the suspended solids or settable 
fraction, are removed from the solution by gravitation to the floor of the container to form sludge under near quiescent conditions. This process also removes settleable organic and inorganic materials and thus reducing the organic load (Al-Asmar, 2006).

Mahvi et al. (2004) studied the removal of anionic surfactants in detergent wastewater by chemical coagualation and found that when ferric chloride, alum and lime were utilized as a coagulant, COD removal percents were $89 \%, 37 \%$ and 21\%, respectively. Aygun and Yilmaz (2010) used coagulation-flocculation process to treat detergent wastewater and found that the optimum dose of the ferric chloride was $2 \mathrm{~g} / \mathrm{L}$ with removal efficiency $71 \%$. Altaher et al. (2011) used ferric chloride coagulant for pretreatment of wastewater streams from petroleum/petrochemical industries and found that $\mathrm{FeCl}_{3}$ had greater efficiency compared with other coagulants with optimum dose of $800 \mathrm{mg} / \mathrm{L}$. Loloei et al. (2019) studied the coagulation process in wastewater treatment of dairy industries and found COD removal efficiency of dairy products industry wastewater was 68 and $62 \%$ at the optimum conditions ( $1 \mathrm{~g} / \mathrm{L}$ at $\mathrm{pH} 5)$ for alum and ferrous sulphate, respectively.

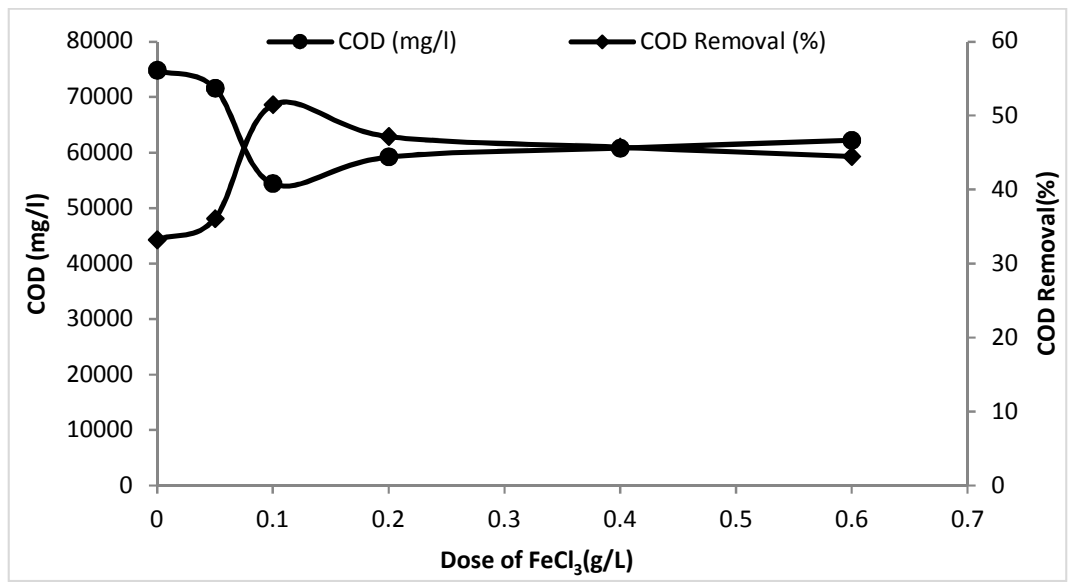

Fig 1: Effect of $\mathrm{FeCl}_{3}$ dosages on the effluent $\mathrm{COD}$ and $\mathrm{COD}$ removal efficiency.

For determination the optimum $\mathrm{pH}$ of ferric chloride, $\mathrm{pH}$ values (4.66-9.33) were examined at ferric chloride dose of $0.1 \mathrm{~g} / \mathrm{L}$ (Fig. 2). It is obvious that, the optimum $\mathrm{pH}$ is 8.36 . Around $\mathrm{pH} 8.39, \mathrm{Fe}$ $(\mathrm{OH})_{3}$ is found which is a hydrophobic compound and can adsorb contaminants in particulate form by surface interactions (Dominguez et al., 2005).

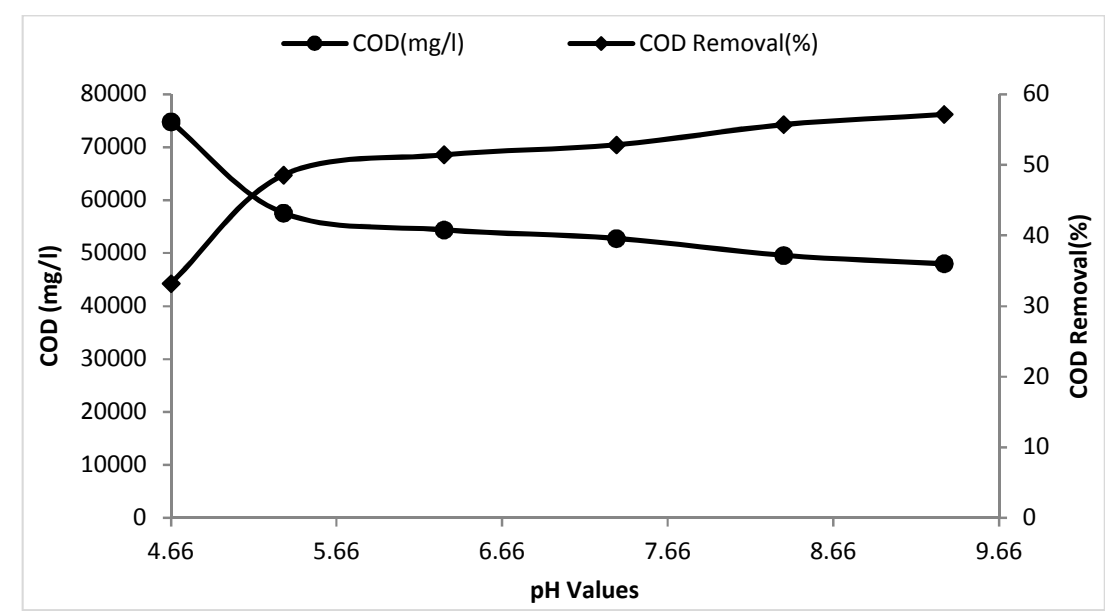

Fig 2: Determination of optimum $\mathrm{pH}$ value at $\mathrm{FeCl}_{3}$ dose of $0.1 \mathrm{~g} / \mathrm{L}$.

El-Gohary et al. (2010) studied pretreatment of personal care products (PCPs) wastewater and found two optimum $\mathrm{pH}$ values, 4.66 in the acidic range and 8.36 in the alkaline range. Aygun and Yilmaz (2010) reported optimum $\mathrm{pH}$ was 11 at $\mathrm{FeCl}_{3}$ dose of $1.5 \mathrm{~g} / \mathrm{L}$ as COD removal efficiency increased 
from $34 \%$ to $57 \%$ when $\mathrm{pH}$ increased from 4 to 11 . Altaher et al. (2011) used ferric chloride coagulant for pretreatment of wastewater streams from petroleum/petrochemical industries and found that the best turbidity removal was achieved at $\mathrm{pH}$ range between 7 and 8.6.

The addition of different doses of polyacrylamide $(0$ to $2.5 \mathrm{~g} / \mathrm{L})$ with constant dose of ferric chloride $(0.1 \mathrm{~g} / \mathrm{L})$ was critically studied at $\mathrm{pH} 8.36$ (Fig. 3). It is clear that the optimum dose of polyacrylamide is $1.5 \mathrm{~g} / \mathrm{L}$. COD removal percentage reached to $70.7 \%$. However, the results obtained indicated that increasing the dose of polymer above $1.5 \mathrm{~g} / \mathrm{L}$, is not significant for COD removal. Synthetic polyelectrolytes are currently the most widely utilized chemicals in industrial wastewaters treatment. In general, small amount of polyelectrolyte is sufficient to attain high efficiency. The use of anionic polyacrylamide raises the flocculation efficiency of the coagulant, decreasing the coagulant amount required for the treatment, raising the settling speed and lowering the process cost (Aguilar $e t$ al., 2005). Coagulation-flocculation process was applied to a slaughterhouse wastewater, utilizing polyacrylamide as coagulant aid to enhance the settling velocity of the flocs (Mudhoo and Ragen, 2011). Flocculants applications not only caused a decrease of turbidity, but also decrease the soluble pollutants concentration and consequently improve other quality parameters of wastewaters (Mostafa, 2013). Aygun and Yilmaz (2010) used coagulation-flocculation process to treat detergent wastewater and reported that the use of $\mathrm{FeCl}_{3}$ with polyelectrolyte as coagulant aids at certain $\mathrm{pH}$ gave higher removal efficiencies (87\%) contrasted to coagulation with $\mathrm{FeCl}_{3}$ alone (71\%).

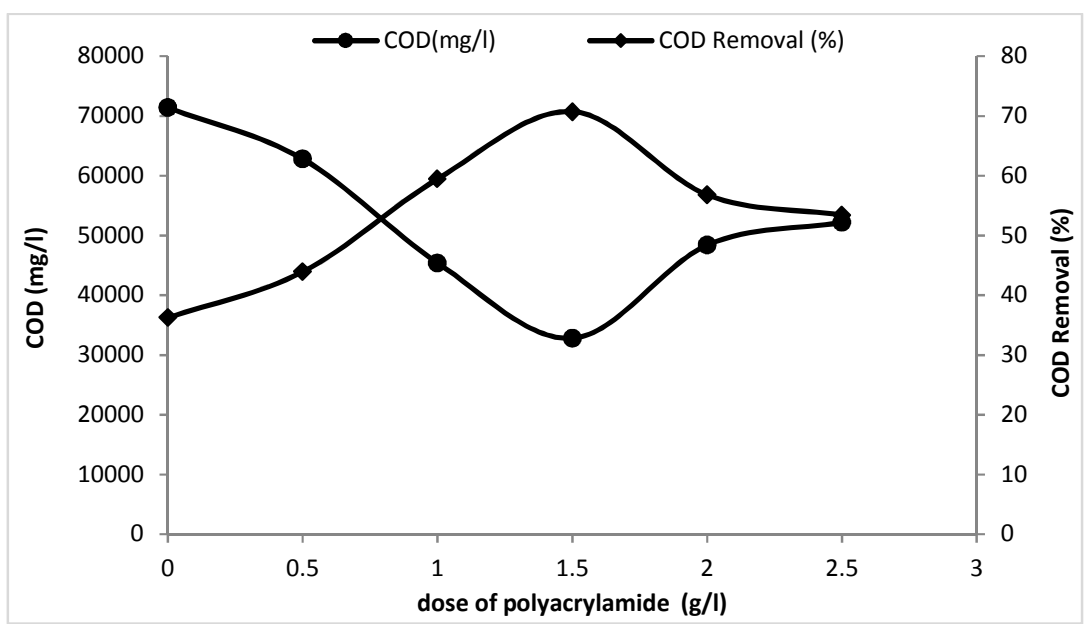

Fig 3: Effect of polyacrylamide dosages on the effluent COD and COD removal efficiency with fixed dose of $\mathrm{FeCl}_{3}(0.1 \mathrm{~g} / \mathrm{L})$ at constant $\mathrm{pH} 8.36$.

The influences of different doses of lime ( 0 to $1.5 \mathrm{~g} / \mathrm{L})$ as coagulant aid in combination with constant dose of ferric chloride $(0.1 \mathrm{~g} / \mathrm{L})$ were examined at $\mathrm{pH} 8.36$ (Fig. 4).

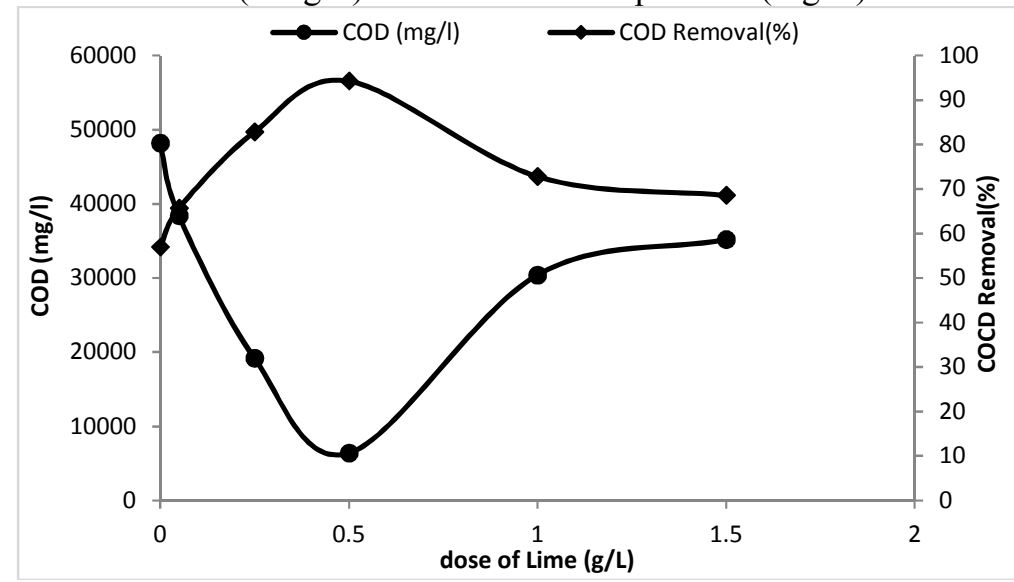

Fig 4: Effect of lime dosages on the effluent COD and COD removal efficiency with fixed dose of $\mathrm{FeCl}_{3}(0.1 \mathrm{~g} / \mathrm{L})$ at constant $\mathrm{pH} 8.36$. 
It is obvious that the optimum dose of lime is $0.5 \mathrm{~g} / \mathrm{L}$ that achieved $94.28 \%$ COD removal. However, the results indicated that increasing lime dose above $0.5 \mathrm{~g} / \mathrm{L}$, has negligible effect on COD removal. Moreover, removal efficiencies were higher than that in case of coagulation with $\mathrm{FeCl}_{3}$ alone. Lime precipitation is very effective in particulate matter removal than other chemical treatment processes (Gursoy-Haksevenler et al., 2014). Aygun and Yilmaz (2010) utilized coagulation-flocculation process for detergent wastewater treatment and found the optimal condition was attained with the dosage $2 \mathrm{~g} / \mathrm{L} \mathrm{FeCl}_{3}$ at $\mathrm{pH} 11$ with COD removal efficiency of (71\%).

\section{Advanced Oxidation Process by Fenton's Reagent}

Fenton reaction is one effective mechanism of Fenton; iron-salt-dependent decomposition of hydrogen peroxide, producing the highly active hydroxyl radical $\left(\mathrm{HO}^{\circ}\right)$, which has a nonselective oxidation properties for organic compounds. Regeneration of $\mathrm{Fe}^{2+}$ through formation of superoxide radical was suggested (Nasr et al., 2016).

To obtain the optimum $\left(\mathrm{Fe}^{2+}\right)$ dose, investigations were carried out using different $\mathrm{Fe}^{2+}$ doses ranged between $0.4 \mathrm{~g} / \mathrm{L}$ and $1.8 \mathrm{~g} / \mathrm{L}$. The results presented in Fig. (5) indicated that the maximum COD removal percent $(93.9 \%)$ was at zero addition of $\mathrm{Fe}^{2+}$. Hence it may be stated that $\mathrm{Fe}^{2+}$ converts into $\mathrm{Fe}^{3+}$ as shown in Eq. (2), which acts as coagulant resulting in improved COD reduction and $\mathrm{Fe}^{3+}$ is already remaining in the sample from the previous coagulation/precipitation process. In addition, according to De Laat and Gallart (1999), the $\mathrm{Fe}^{3+}$ remained can react with $\mathrm{H}_{2} \mathrm{O}_{2}$ to generate $\mathrm{Fe}^{2+}$ and hydroperoxyl radicals $\left[\mathrm{HO}_{2}{ }^{\circ}\right]$ in the reaction medium (Eq.3)

$$
\begin{aligned}
& \mathrm{Fe}^{2+}+\mathrm{H}_{2} \mathrm{O}_{2} \rightarrow \mathrm{Fe}^{3+}+\mathrm{HO}^{-}+\mathrm{HO}^{-} \\
& \mathrm{Fe}^{3+}+\mathrm{H}_{2} \mathrm{O}_{2} \rightarrow \mathrm{HOO}^{\bullet}+\mathrm{Fe}^{2+}+\mathrm{H}^{+}
\end{aligned}
$$

The oxidation capacity of $\mathrm{HOO}^{*}$ is less comparable to $\mathrm{OH}^{*}$, which affects the overall $\mathrm{COD}$ reduction (Nasr et al., 2016). It is desirable that the ratio of $\mathrm{H}_{2} \mathrm{O}_{2}$ to $\mathrm{Fe}^{2+}$ should be as small as possible, so that the COD removal was not significant due to the remaining of $\mathrm{Fe}^{+3}$ in the sample from the previous coagulation process. Only $52 \%$ of TC was removed by Photo catalytic AOPs (Azat, 2017). Therefore, there is no need for the addition of $\mathrm{Fe}^{2+}$ to the reaction mixture to minimize the cost of treatment and reduce the formed sludge.

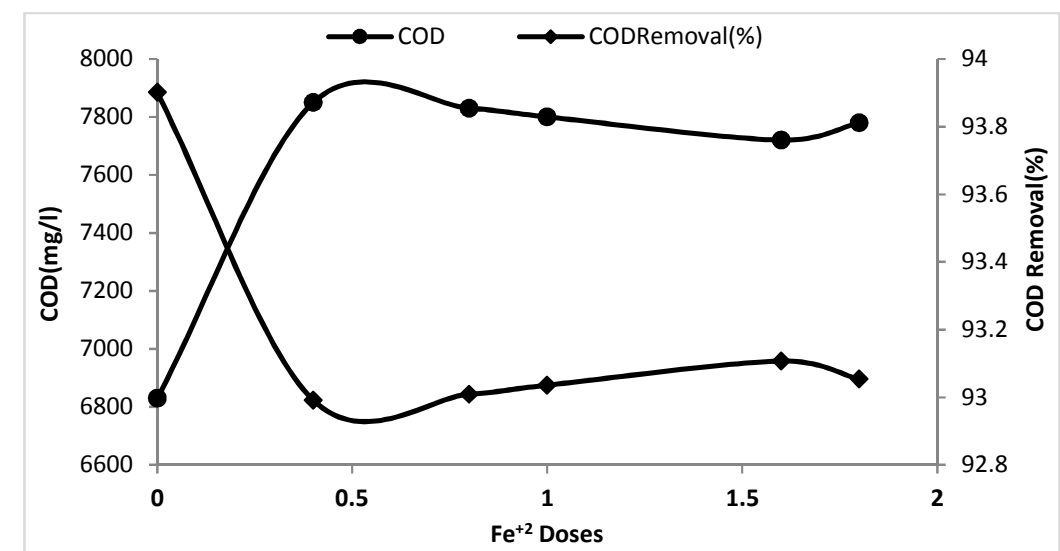

Fig. 5: Determination of optimum dose of $\mathrm{Fe}^{+2}$ in Fenton reaction after coagulation by $\mathrm{FeCl}_{3}$ with lime.

Different $\mathrm{pH}$ values ranging from 1.77 to 8.41 were investigated. The dose of $\mathrm{H}_{2} \mathrm{O}_{2}$ was kept constant at $(20 \mathrm{ml})$. The optimum $\mathrm{pH}$ value (Fig. 6) was 7.35 where the higher COD removal $(94.58$ $\%)$ was achieved. Loannou et al. (2013) who treated winery wastewater using Fe (II) $=10 \mathrm{mg} / \mathrm{L}$, $\left[\mathrm{H}_{2} \mathrm{O}_{2}\right]=100 \mathrm{mg} / \mathrm{L}$ and COD removal was $35 \%$ at $\mathrm{pH} 3.5$. 


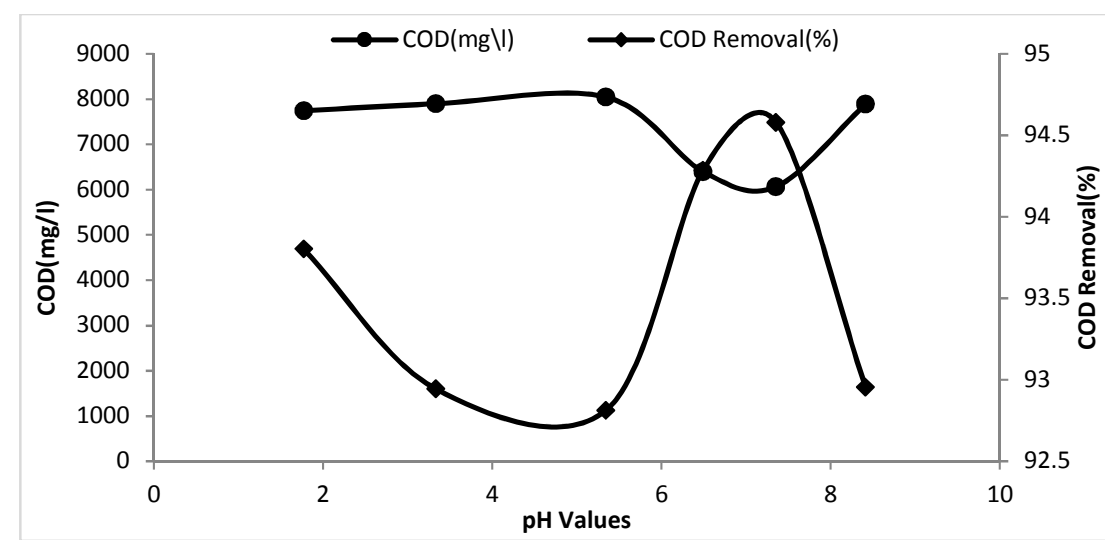

Fig. 6: Determination of optimum $\mathrm{pH}$ value of $\mathrm{H}_{2} \mathrm{O}_{2}$ in Fenton reaction after coagulation by $\mathrm{FeCl}_{3}$ with lime.

The effect of $\mathrm{H}_{2} \mathrm{O}_{2}$ on the COD reduction has been studied. It is expected that as dose of $\mathrm{H}_{2} \mathrm{O}_{2}$ to pollutant increased, more hydroxyl radicals are available to descent the organic pollutants and therefore accelerate their decadence. To obtain the optimum $\mathrm{H}_{2} \mathrm{O}_{2}$ dose, investigations were carried out using different $\mathrm{H}_{2} \mathrm{O}_{2}$ volumes $(0$ to $40 \mathrm{ml})$. The results indicated that significant enhancement of the COD removal at $\mathrm{H}_{2} \mathrm{O}_{2}$ dose of $30 \mathrm{ml}$. Therefore the dose of $(30 \mathrm{ml})$ has been selected as shown in Fig. (7). The increase in COD removal is comparable to the results presented Gulkaya et al. (2006) and Kang and Hwang (2000). Adding of $\mathrm{H}_{2} \mathrm{O}_{2}$ in amount overrides the stoichiometric ratio of COD: $\mathrm{H}_{2} \mathrm{O}_{2}=1: 1\left(55 \mathrm{~g} / \mathrm{L} \mathrm{H}_{2} \mathrm{O}_{2}\right)$ did not improve the respective maximal organic degradation (Jain et al., 2018). This may be due to auto-decay of $\mathrm{H}_{2} \mathrm{O}_{2}$ to oxygen and water (Eq. 4) and the recombination of $\mathrm{OH}^{*}$ radicals (Eq. 6) or play as a scavenger for the $\mathrm{OH}^{*}$ radicals according to Haber and Weiss (1934) (Eq.5)

$$
\begin{aligned}
& \mathrm{H}_{2} \mathrm{O}_{2} \rightarrow 2 \mathrm{H}_{2} \mathrm{O}+\mathrm{O}_{2} \ldots \ldots \ldots \ldots \ldots \ldots \ldots \\
& 2 \mathrm{OH}^{*} \leftrightarrow \mathrm{H}_{2} \mathrm{O}_{2} \ldots \ldots \ldots \ldots \ldots \ldots \ldots \\
& \mathrm{HO}^{\circ}+\mathrm{H}_{2} \mathrm{O}_{2} \rightarrow \mathrm{H}++\mathrm{H}_{2} \mathrm{O}+\mathrm{OO}^{-}
\end{aligned}
$$

Since the $\mathrm{OH}$ radical reacts with $\mathrm{H}_{2} \mathrm{O}_{2}$, the $\mathrm{H}_{2} \mathrm{O}_{2}$ itself plays as the $\mathrm{OH}^{*}$ scavenger (Nasr et al., 2016). Therefore, the $\mathrm{H}_{2} \mathrm{O}_{2}$ should be optimally added to achieve the best degradation. Mandal et al. (2010) used $[\mathrm{Fe}(\mathrm{II})]=6 \mathrm{~g} / \mathrm{L}$ and $\left[\mathrm{H}_{2} \mathrm{O}_{2}\right]=220 \mathrm{~g} / \mathrm{L}$ in the treatment of industrial wastewater and obtained COD removal $=\sim 95 \%$ where the optimum condition of $\left[\mathrm{H}_{2} \mathrm{O}_{2}\right]=300-600 \mathrm{mg} / \mathrm{L}, \mathrm{Fe}(\mathrm{II})=10$ $\mathrm{mg} / \mathrm{L} ; \mathrm{pH}=3-3.5$, room temperature and reaction time $=6 \mathrm{~h}$ were chosen by Yalfani et al. $(2009)$ in the treatment of Phenol by the homogeneous Fenton reaction.

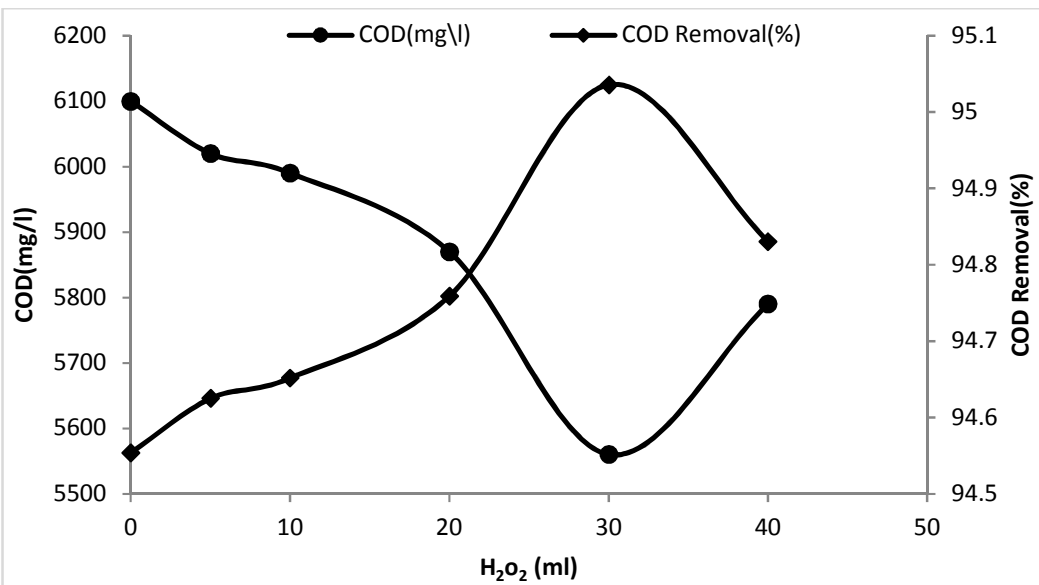

Fig 7: Determination of optimum volume of $\mathrm{H}_{2} \mathrm{O}_{2}(\mathrm{ml})$ at $\mathrm{pH}=7.35$ in Fenton reaction after coagulation by $\mathrm{FeCl}_{3}$ with lime. 


\section{Conclusion}

It was observed that the dairy industry wastewater is easily amenable to physicochemical treatment. This treatment will help in reducing the organic load to facilitate the biological treatment. The results discussed above indicated that the maximum COD removal efficiency (94.2\%) was obtained from the combination of $\mathrm{FeCl}_{3}$ /lime. COD removal efficiency of polyacrylamide with $\mathrm{FeCl}_{3}$ was $70.7 \%$. Applying Fenton oxidation process after coagulation with $\mathrm{FeCl}_{3}$ and lime was achieved a little refinement in the COD removal. The optimal operating conditions were; zero $\mathrm{Fe}^{2+}, 30 \mathrm{ml}$ of $\mathrm{H}_{2} \mathrm{O}_{2}(30 \%)$ and $7.35 \mathrm{pH}$, the COD removal efficiency was $94.5 \%$.

\section{References}

Adams, V.D., 1991. Water and Wastewater Examination Manual.Lewis Publishers, INC., Michigan, USA.

Aguilar, M.I., J. Sáez, M. Lloréns, A. Soler, J.F. Ortuño, V. Meseguer and A. Fuentes, 2005. Improvement of coagulation-flocculation process using anionic polyacrylamide as coagulant aid. Chemosphere, 58(1): 47-56.

Ahmad, R., Z. Ahmad, A.U. Khan, N.R. Mastoi, M. Aslam and J. Kim, 2016. Photocatalytic systems as an advanced environmental remediation: Recent developments, limitations and new avenues for applications. Journal of Environmental Chemical Engineering, 4(4): 4143-4164.

Al-Asmar, A., 2006. Impact of some industrial activities on the surrounding environment, Damietta, Egypt, PhD. Thesis, Faculty of Sci. Damietta, Mansoura University.

AlMubaddal, F., K. AlRumaihi and A. Ajbar, 2009. Performance Optimization of Coagulation/Flocculation in the Treatment of Wastewater from a Polyvinyl Chloride Plant. Journal of Hazardous Materials, 161, 1, 431-438. doi:10.1016/j.jhazmat.2008.03.121.

Altaher, H., E. ElQada and W. Omar, 2011. Pretreatment of Wastewater Streams from Petroleum/Petrochemical Industries Using Coagulation. Advances in Chemical Engineering and Science, 1, 245-251.

Amud, O.S. and I.A. Amoo, 2007. Coagulation/flocculation process and sludge conditioning in beverage industrial wastewater treatment. Journal of Hazardous Materials, 141(3): 778-783.

APHA, 2017. Standard Methods for the Examination of Water and Wastewater. 23 ${ }^{\text {rd }}$ Ed., American Public Health Association, American Water Works Association and Water Environment Federation, NW, Washington, DC, USA, 20001-3710.

Asadi, M., 2006. Beet-sugar handbook. John Wiley \& Sons.

Aygun, A. and T. Yilmaz, 2010. Improvement of coagulation-flocculation process for treatment of detergent wastewaters using coagulant aids. International Journal of Chemical and Environmental Engineering, 1 (2): 97-101.

Azat, Y., 2017. Photocatalytic Degradation of Organic Pollutants in wastewater. MSc. Chemical Engineering Department, Nazarbayev University.

Benatti, C.T. and C.R.G. Tavares, 2012. Fenton's process for the treatment of mixed waste chemicals. In: Organic pollutants ten years after the Stockholm convention-Environmental and analytical update. 247-270. https://doi.org/10.5772/31225.

De Laat, J. and H. Gallart, 1999. Catalytic decomposition of hydrogen peroxide by Fe (III) in homogeneous aqueous solution: mechanism and kinetic modeling, Environ. Sci. Technol., 33, 2726-2732.

Deshannavar, U.B., R.K. Basavaraj and M.N. Nandini, 2012. High rate digestion of dairy industry effluent by upflow anaerobic fixed-bed reactor, Journal of Chemical and Pharmaceutical Research, 4(6): 2895-2899.

Dominguez, J.R., J. Beltrán de Heredia, T. González and F.G. Sanchez-Lavado, 2005. Evaluation of ferric chloride as a coagulant for cork processing wastewaters. Influence of the operating conditions on the removal of organic matter and settleability parameters, Industrial \& Engineering Chemistry Research, 44(17): 6539-6548.

El-Gohary, F., A. Tawfik and U. Mahmoud, 2010. Comparative study between chemical coagulation/precipitation $(\mathrm{C} / \mathrm{P})$ versus coagulation/dissolved air flotation (C/DAF) for pretreatment of personal care products (PCPs) wastewater. Journal of Desalination, 252 (1-3): 106112. Doi:10.1016/j.desal.2009.10.016. 
Farizoglu, B. and S. Uzuner, 2011. The investigation of dairy industry wastewater treatment in a biological high performance membrane system. Biochemical Engineering Journal, 57, 46-54. DOI:10.1016/j.bej.2011.08.007.

Gu, L., Y. Wang, N. Zhu, D. Zhang, S. Huang, H. Yuan, Z. Lou and M. Wang, 2013. Preparation of sewage sludge based activated carbon by using Fenton's reagent and their use in 2-naphthol adsorption. Bioresour. Technol., 146, 779-784.

Gulkaya, I., G.A. Surucul and F.B. Dilek, 2006. Importance of $\mathrm{H}_{2} \mathrm{O}_{2} / \mathrm{Fe}^{2+}$ ratio in Fenton's Treatment of a carpet Dyeing wastewater. J. Hazard. Matter.136, 763-769.

Gursoy-Haksevenler, B.H., S. Doğruel and I. Arslan-Alaton, 2014. Effect of ferric chloride coagulation, lime precipitation, electrocoagulation and the Fenton's reagent on the particle size distribution of olive mill wastewater. International Journal of Global Warming, 6 (2-3): 194211. DOI: 10.1504/IJGW.2014.061010.

Haber, F. and J. Weiss, 1934. The catalytic decomposition of hydrogen peroxide by iron salts, Proc. Roy. Soc. Lond., 147, 332-351.

Jain, B., A.K. Singh, H. Kim, E. Lichtfouse and K.V. Sharma, 2018. Treatment of organic pollutants by homogeneous and heterogeneous Fenton reaction processes. Environmental Chemistry Letters, 16, 947-967. Doi.org/10.1007/s10311-018-0738-3.

Kang, Y.W. and K.Y. Hwang, 2000. Effects of Reaction Conditions on the Efficiency in the Fenton process. Water Research, 34(10): 2786-2790.

Khouni, I., B. Marrot, P. Moulin and R.B. Amar, 2011. De-colourization of the Reconstituted Textile Effluent by Different Process Treatments: Enzymatic Catalysis, Co-agulation/Flocculation and Nanofiltration Processes. Desalination, 268, 27-37. doi:10.1016/j.desal.2010.09.046

Loannou, L., T. Velegraki, C. Michael, D. Mantzavinos and D.F. Kassinos, 2013. Sunlight, iron and radicals to tackle the resistant leftovers of bio treated winery wastewater. Photochem Photobiol Sci, 12, 664-670. https://doi.org/10.1039/C2PP25192B.

Loloei, M., H. Alidadi, G. Nekonam and Y. Kor, 2019. Study of the coagulation process in wastewater treatment of dairy industries. International Journal of Environmental Health Engineering, 2(5): 17-21.

Mahvi, A.H., A. Maleki and B. Roshani, 2004. Removal of Anionic Surfactants in Detergent Wastewater by Chemical Coagualation. Pakistan Journal of Biological Sciences, 7, 12, 22222226.

Mandal, T., S. Maity, D. Dasgupta and S. Datta, 2010. Advanced oxidation process and bio treatment: their roles in combined industrial wastewater treatment. Desalination, 250 (1): 87-94. https://doi. org/10.1016/j.desal.2009.04.012.

Mostafa, A. A., 2013. Treatment of cheese processing wastewater by physicochemical and biological methods. International Journal of Microbiological Research, 4, 321-332.

Mudhoo, A. and A.K. Ragen, 2011. Performance of four polyelectrolytes as flocculation aids in the primary treatment of textile. International Journal of Environmental Waste Management, 5(34): 211-223.

Nasr, F.A., I. Abdelfattah, A.M. Shana and M.M. Abo-Aly, 2016. Fenton Oxidation Process of Refractory Organics in Gas Processing Wastewater. Egypt. J. Chem. 59(2): 241- 252.

Papic, S., N. Koprivanac and A.L. Bozic, 2000. Removal of Reactive Dyes from Wastewater Using Fe(III) Coagulant, Coloration Technology, Vol. 161, No. 11, pp. 352-358.

Patil, C. and M. Hugar, 2015.Treatment of dairy wastewater by natural coagulants. International Research Journal of Engineering and Technology (IRJET), 2 (4): 1120-1125.

Prazeres, A.R., F. Carvalho and J. Rivas, 2013. Fenton-like application to pretreated cheese whey wastewater. Journal of Environmental Management, 129, 199-205.

Rump, H.H., 1999. Laboratory manual for the examination of water, waste water and soil, $3^{\text {rd }}$ Ed., Wiley-VCH Verlag GmbH.

Shete, B.S. and N.P. Shinkar, 2013. Dairy Industry Wastewater Sources, Characteristics and its Effects on Environment. International Journal of Current Engineering and Technology, 3 (5): 1611- 1615 .

Sivaprakasam, S. and K. Balaji, 2019. Applications of Sequencing Batch Reactor in the Degradation of Dairy Industry Wastewater. International Journal of Recent Technology and Engineering (IJRTE), 8 (2): 2277-3878. 
Slavov, A.K., 2017. Dairy wastewaters, General characteristics and treatment possibilities, A Review. Food Technology and Biotechnology, 55 (1): 14-28. Doi: 10.17113/ftb.55.01.17.4520.

Suman, A., T. Ahmad and K. Ahmad, 2017. Dairy wastewater treatment using water treatment sludge as coagulant: a novel treatment approach, Environ Dev Sustain, 15(5): 1-14. DOI $10.1007 / \mathrm{s} 10668-017-9956-2$

Tawfik, A., M. Sobhey and M.Badawy, 2008. Treatment of a combined dairy and domestic wastewater in an up-flow anaerobic sludge blanket (UASB) reactor followed by activated sludge (AS system). Desalination, 227, 167-177.

Yalfani, M.S., S. Contreras, F. Medina and J. Sueiras, 2009. Phenol degradation by Fenton's process using catalytic in situ generated hydrogen peroxide, Appl Catal B Environ, 89, 519-526. https://doi. org/10.1016/j.apcatb.2009.01.007.

Ying, G.G., B. Williams and R. Kookana, 2002. Environmental fate of alkyl phenols and alkyl phenol ethoxylates - a review. Journal of Environment International, 28(3): 215-226. 